Bimini, the Bellairs Institute of McGill University in Barbados, the Caraibisch Marien-Biologisch Institut in Curacao, the University College of the West Indies in Jamaica and the Universities of Oriente, Villaneuva and Nacional and the Oficina Hidrográfica in Cuba. Several of these institutes are less than three years old, and this was the first occasion on which most of the participants had met each other. The conference was restricted to laboratories established on islands in the area of reef-building corals of the tropical western Atlantic, which extends from the easterm islands of the Caribbean to Bermuda. Throughout this great sea area the marine flora and fauna and the hydrographic conditions are remarkably uniform, and in consequence the participants found a considerable field of common interest in the problems with which they are concerned.

The conference was felt to be of such value by the participants that a permanent Association of Island Marine Laboratories was established to keep its members in touch with each other, to exchange information and to co-operate in research programmes that affect the whole area. The Association hopes also to arrange visits and exchange of experts in special fields of study. A publication is to be issued shortly, giving information on the facilities for research offered by the member institutes, and consideration is being given to the founding of a journal to publish papers on the biology of the area. It is hoped to hold the next conference of the Association in Bermuda in 1958. Prof. D. M. Steven, of the University College of the West Indies, was elected its first president, and Dr. Juan Rivero, director of the Marine Laboratory of the University of Puerto Rico, its secretary.

\section{English Translations of Russian Medical and Biological Journals}

The Pergamon Institute, London (4-5 Fitzroy Square, W.1) and New York, is a non-profit-making foundation which has been formed for the purpose of making available to English-speaking scientists, medical men and engineers, the results of research in the U.S.S.R. It has the support of an honorary advisory council containing the names of distinguished research workers from many different countries. The formation of the Institute was stimulated by the recent report of the United Kingdom Government Advisory Council on Scientific Policy (Nature, 178, 1255; 1956), which suggested that only about 2 per cent of British working scientists can read Russian compared with $80-90$ per cent who read French and 60 per cent who read German. As part of its activities, the Institute has just started the complete translation of a number of Russian medical and biological journals, the first to appear being the Journal of Microbiology, Epidemiology and Immunobiology (from Vol. 28, issued in monthly parts ; annual subscription £18), Biophysics (from Vol. 2, eight issues per annum, $£ 10$ 14s.), Problems of Virology (Vol. 2, bimonthly, $£ 7$ p.a.) and Problems of Hematology and Blood Transfusion (Vol. 2, monthly, $£ 7$ p.a.). The Physiological Journal of the U.S.S.R. (Sechenov) and Problems of Oncology will also be translated.

Publication is supported financially by the National Institutes of Health, United States Department of Health, Education and Welfare. It has been possible to arrange for early copies of the journals and the original illustrations to be made available from the U.S.S.R. with the result that publication has been astonishingly prompt : some of the original papers bear dates in late 1956. The translations read easily and the printing and production are of high quality. The bibliographies of the papers are set out very clearly and they show that Russian workers are making a lot of use of journals from English-speaking countries. These translations will help to make the transmission of information a more mutual one. The continued success of the scheme will depend on a sufficient supply of translators to carry on the work, and the Institute invites offers from suitably qualified people who would be willing to help. Translations of individual papers in Russian, and also of some scientific journals, are already available from Consultants Bureau, Inc., 227 West 17th Street, New York, but the Pergamon Institute has the advantage that it is a non-profit-making body.

\section{Biochemistry of Sulphur}

A COLLOQUIUM on the biochemistry of sulphur was held in May 1956 in the biological station at Roscoff, at which thirty-four invited specialists from seven countries took part. The papers which were given and the discussions which followed have now been published (Colloque sur la Biochimie du Soufre, Roscoff, 14-18 Mai 1956. Pp. 244. Paris : Editions du Centre National de la Recherche Scientifique 1956). In his introduction, Prof. C. Fromageot points out that in living matter sulphur occurs in a variety of forms-as thiols, disulphides, thioethers and heterocyclic compounds, whereas phosphorus occurs only as orthophosphates or their anhydrides. New techniques, particularly those of chromatography and the use of radioactive sulphur, have led in the past few years to a rapid increase in knowledge of the biochemical transformations and catalytic actions of substances containing sulphur. The main emphasis at the meeting was on sulphur compounds in the higher animals, though the first two sessions contained papers on the sulphur metabolism of micro-organisms. In the third session Prof. P. Handler dealt with the last stages in the oxidation of cysteine, and described experiments leading to the unexpected discovery that hypoxanthine may act in conjunction with lipoic acid as a reducible carrier in the oxidation of sulphite in animal tissues. Sulphatases were discussed by K. S. Dodgson and by B. Spencer and the metabolism of steroid sulphates by A. B. Roy. Administration of inorganic sulphate containing radioactive sulphur to some of the higher animals showed that the sulphur is incorporated into organic compounds in a manner which differs according to the species of animals used (P. B. Pearson). Ruminants incorporated inorganic sulphur at a rate sufficient to be of nutritional importance, probably owing primarily to activities of micro-organisms in the alimentary tract. This paper produced a lively discussion which included the plea that the term 'detoxication', with its teleological implications, should be dropped from the biochemical vocabulary. Among other topics included in the Colloquium were the metabolism of sulphur in relation to vitamins of the B group, the metabolism of cystamine, and enzymic reactions involving thioesters. In the review copy of this book, pages 113-128 were omitted and duplicates of other pages bound in their place. 